\title{
Women's experience with pain during hysterosalpingographic investigation in Calabar, South-South Nigeria
}

Mabel Ikpim Ekott ${ }^{1 *}$, Akpan Ubong Bassey ${ }^{1}$, Oku Oboku², Bassey Darlene ${ }^{3}$ and Udo Atim Edet ${ }^{1}$

*Correspondence: mekotts@yahoo.com

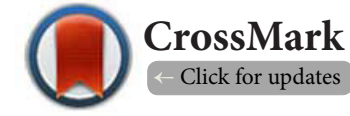

'Department of Obstetrics and Gynaecology, University of Calabar, Nigeria. ${ }^{2}$ Department of Anaesthesiology, University of Calabar, Calabar, Nigeria.

${ }^{3}$ Department of Radiology, University of Calabar, Calabar, Nigeria.

\begin{abstract}
Background: Hysterosalpingogram is a useful investigation for evaluation of infertility. However the procedure is associated with variable degrees of pain and discomfort.

Objective: The objectives of the study were to determine the intensity of pains experienced by women during the investigation, the management of the pains by providers and women's expectation and satisfaction with their pain management.

Methodology: This was a prospective cohort study involving women who had Hysterosalpingography at radiologic centres in Calabar between July 2013 and June 2014. Structured self-administered questionnaire was used to collect data on demographic profile, pre and post procedure care, pain intensity, its management and women's satisfaction with their care. Data were analyzed using SPSS 16. Statistically significant level was set at $<0.5$.

Results: The analysis was based on 93 returned completed questionnaire. The mean age was $33 \pm 6.03$ (SD). About half $51(54.8 \%)$ of the women had tertiary level of education and $49(52 \%)$ were nulliparous. The commonest indication for HSG was infertility 69(74.2\%). Pain experienced was rated as severe (7-10) by 29(31.2\%) women and moderate (4-6) by 35(37.6\%). Pre-procedure analgesics were administered to $45(48.5 \%)$ women. Most women were satisfied with their pre $55(59 \%)$ and post $50(53.8 \%)$ procedure care. However, satisfaction was not significantly influenced by the severity of the pain experienced $p=0.4$.

The study revealed that majority of the women experienced moderate to severe levels of pain and in most cases use of analgesics during HSG procedure was inadequate. Proper and adequate pain management should be integrated into the procedure.
\end{abstract}

Keywords: Hysterosalpingogram, pain, analgesics, satisfaction, infertility, women, perception

\section{Introduction}

Hysterosalpingogram [HSG] is often requested as part of first line investigations for women with infertility, menstrual abnormalities and congenital or acquired uterine disorders [1-4]. Tubal pathology contributes to $60 \%$ of female infertility in Nigeria and HSG is often the first line test in most centres offering infertility care [2,5-7]. It provides a view of the uterine cavity and the fallopian tubes which allows detection of endometrial and tubal pathologies $[4,8]$. It is often performed as an outpatient procedure preferably in the follicular phase of the menstrual cycle. Its limitation may include inability to show tubo-peritoneal pathology which may require laparoscopic chromo-pertubation to diagnose intra-peritoneal lesions [6,9]. HSG has also been known to have some therapeutic value as there could be spontaneous resolution of infertility due to dislodgment of mucous plugs from the fallopian tubes during the procedure [10-12].

The investigation however has been associated with different degrees of painful experience by women which has made it a dreaded investigation [13-15]. The pain felt by women at HSG 
may arise from manipulation of the cervix during canulation, distension of the uterus and fallopian tubes and peritoneal irritation with contrast media and anxiety. Pain is a noxious stimulus that should be alleviated or eliminated. It could on some occasions cause vaso-vagal shock, collapse of patients and user dissatisfaction.

Several measures to reduce the pain at hysterosalpingography include use of balloon catheters, local anaesthetic agents and analgesic [7-9]. A meta analysis showed that use and none use of pharmacological agents did not significantly alter the intensity of pains experienced by women undergoing the investigation [11]. On the other hand, in another study of review of pains during HSG it was found that gentle handling of patients and use of balloons were associated with reduced pains [12]. Also, a previous study found that pain was worse at the point of instilling constrast media and a combination of nonsteroidal analgesic and paracervical block was associated with less pain [8]. Anaesthesia is not used during HSG because it is an outpatient procedure and patients need to get back home in a fully conscious state. Some studies found some relief of pain with injection of intravenous Opioids during the procedure but the side effects and cost are possible limitations [9].

It is pertinent to look at pain management as an indicator of the quality of care in this invasive procedure. Therefore this study was conducted in Calabar, Nigeria to determine the intensity of pains experienced by the women during the investigation, the management of the pains by providers and women's expectation and satisfaction with their pain management.

\section{Methodology \\ Setting}

Calabar is the capital of Cross River State in the South -South Nigeria. The state boasts of a Teaching hospital and several secondary health care facilities and private health facilities where primary investigation of infertility takes place. Women who visited the Teaching Hospital and private health facilities for investigation of infertility and other gynaecological problems requiring HSG were recruited to the study. The participants had hysterosalpingogram at the Teaching hospital and major diagnostic facilities in Calabar.

\section{Design}

This was a prospective cross sectional study of women who had hysterosalpingography during the period July 2013- December 2014. Ethical approval was obtained from the ethics committee of University of Calabar Teaching Hospital. The objectives and methodology of the study were explained to the women who gave informed consent. The patients were instructed by their health care providers on how to complete the questionnaire which evaluated their bio-demographic data, pre and post procedure care and visual analogue scale. The questionnaire was issued to the women along with the request forms for HSG. They were trained and instructed to complete the form as soon as they were comfortable enough to do so within 24 hours of the procedure. Completed forms were returned to the requesting doctor and collected by the researchers for analysis. We excluded women with acute pelvic infection and those who declined to participate in the study.

Women marked on the visual analogue scale which was marked 0-10 on their questionnaire the worst level of pain they experienced in the course of the procedure. The score of 0 was for no pain and 10 the worst possible pain experienced. Service providers who performed the hysterosalpingography were blinded to the study. Women were asked to indicate as satisfied, dissatisfied, no opinion and their level of satisfaction with their pain management

\section{Data analysis}

Data were entered into Excel spread sheet. Pain score of 0-3 was graded as mild, 4-6 moderate and 7-10 severe pains. The data were analyzed using statistical package for Social Science 16 . Simple percentages were calculated and categorical variables were compared using chi square test. The level of statistical significance was set at $<0.05$.

\section{Results}

A total of 93 (96\%) out of 97 women returned the completed pain care assessment questionnaire. The mean age of the women was $33 \pm 6.03(\mathrm{sd})$. Forty-five (49\%) were between $35-39$ years of age. Nulliparae[49] constituted $52 \%$ of the patients and $51(54 \%)$ had tertiary level of education (Table 1).

Table 1. The characteristics of the patients.

\begin{tabular}{lll}
\hline Variable & Frequency & Percentage \\
\hline Age[years] & & \\
$20-29$ & 29 & 31.2 \\
$30-39$ & 46 & 49.5 \\
$40-49$ & 18 & 19.4 \\
Total & 93 & 100 \\
Mean \pm SD & $33 \pm 6.03$ & \\
\hline Educational level & & \\
\hline None & 1 & 1.1 \\
Primary & 8 & 8.6 \\
Secondary & 33 & 35.5 \\
Tertiary & 51 & 54.8 \\
Total & $\mathbf{9 3}$ & $\mathbf{1 0 0 . 0}$ \\
\hline Parity & & \\
\hline 0 & 49 & 52.7 \\
1 & 26 & 28.0 \\
2 & 10 & 10.8 \\
3 & 8 & 8.6 \\
Total & $\mathbf{9 3}$ & $\mathbf{1 0 0}$ \\
\hline
\end{tabular}


Infertility was the main reason for requesting HSG in 69(74\%) women and uterine fibroid in 10 (10.8\%) of them Table 2.

Pre-procedure care (Table 3) showed Fifty seven (61.3\%) women were informed the procedure would be painful by the requesting doctor and $47(50.5 \%)$ had pain care discussed preoperatively by the radiologists or radiographers while 45 $48.4 \%$ ) had preoperative analgesia prescribed by the requesting doctors.

Table 2. The indications for hysterosalpingogram.

\begin{tabular}{lll}
\hline Variable & Frequency & Percentage \\
\hline Indications for test & & \\
No menses & 1 & 1.1 \\
Infertility & 69 & 74.2 \\
Fibroids & 10 & 10.8 \\
Abnormal uterine bleeding & 5 & 5.4 \\
Painful menses & 8 & 8.6 \\
Total & 93 & 100 \\
\hline
\end{tabular}

Table 3. The intensity of pain experienced by the patients.

\begin{tabular}{|c|c|c|}
\hline Intensity of pains & Frequency & Percentage \\
\hline Mild [0-3] & 29 & 31.2 \\
\hline Moderate [4-6] & 35 & 37.6 \\
\hline Severe [7-9] & 29 & 31.2 \\
\hline \multicolumn{3}{|c|}{$\begin{array}{lc}\text { Mean pain score } & 5.7 \text { SD } 2.5 \\
\text { Factors associated with pain perception }\end{array}$} \\
\hline ble & $\begin{array}{l}\text { ception } \\
\text { derate [\%] }\end{array}$ & Severe[\%] \\
\hline
\end{tabular}

\begin{tabular}{|c|c|c|c|c|}
\hline \multicolumn{5}{|l|}{ Age } \\
\hline$\leq 33$ & $39[73.6]$ & $14[26.4]$ & & \\
\hline$>33$ & $25[62.5]$ & $15[37.5]$ & 1.31 & 0.25 \\
\hline \multicolumn{5}{|c|}{ Educational level } \\
\hline$\leq$ Primary & $6[66.7]$ & $3[33.3]$ & & \\
\hline$>$ Primary & $58[69.0]$ & $26[31.0]$ & & 1.00 \\
\hline \multicolumn{5}{|l|}{ Parity } \\
\hline Nulliparous & $31[63.3]$ & $18[36.7]$ & & \\
\hline Parous & $33[75.0]$ & $11[25.0]$ & 1.49 & 0.22 \\
\hline
\end{tabular}

Evaluation of pain experienced and its management showed the mean pain score experienced was $5.7 \pm 2.5(\mathrm{sd})$. Severe pain [7-10] was experienced by 29(31.2\%) and moderate pain [4-6] by 35(37.6\%). The severity of pains was not significantly influenced by the age $(P=0.25)$, educational level $(P=1.0)$ or Parity $(P=0.22)$ of the women (Table 4). Intra-operative pain care showed 51(54.8\%) women who complained of pains were asked to tolerate the pain by the attending service provider. Injections were administered to $8(8.6 \%)$ women to ameliorate their pains. Post procedure, $45(48.4 \%)$ of the women received no pain medication and 14 (15.1\%) received non-steroidal anti-inflammatory drugs.

Table 4. Management of pain.

\begin{tabular}{llll}
\hline Pre-procedure care & & & \\
\hline Variable & Yes (\%) & No (\%) & Total \\
\hline Pain Discussed with client & $57(61.3)$ & $36(38.7)$ & $93(100)$ \\
Pain care Discussed & $47(50.5)$ & $46(49.5)$ & $93(100)$ \\
Pre-op Analgesics & $45(48.4)$ & $48(51.6)$ & $93(100)$ \\
\hline Intra-procedural & & \\
\hline Given tablets & 51 & 54.8 \\
Reassured & 14 & 15.1 \\
Given injection & 8 & 8.6 \\
Asked to tolerate pains & 2 & 2.2 \\
Nothing was done & 18 & 9.6 \\
\hline Post procedure medications & & \\
\hline Non steroidal analgesics & 14 & 15.1 \\
Hyoscine & 6 & 6.5 \\
Paracetamol & 4 & 4.3 \\
Parcetamol and Hyosine & 2 & 2.2 \\
Do not know name of drugs & 22 & 23.7 \\
None & 45 & 48.4 \\
Total & 93 & 100 \\
\hline
\end{tabular}

The level of satisfaction with their care was as depicted in Table 5. Equal numbers of women indicated they were satisfied with their pre-procedure counseling 54(58.1\%), pain care 55(59.1\%) and post procedure care 50(53.8\%). The level of satisfaction was not influenced by the severity of pains experienced during their care $(\mathrm{P}=0.423)$.

Asked, how they would have loved the procedure to be performed, most $65(70 \%)$ would have preferred it painless, $18(19 \%)$ would prefer preoperative analgesia while $9(10 \%)$ would prefer sedation. Only $1(1 \%)$ felt she could bear the pain.

\section{Discussion}

Our study showed that the commonest reason for hysterosalpingogram was infertility. Moderate to severe pain was experienced by $68 \%$ of the women. Inadequate attention to the painful aspect of hystersoalpingogram by service providers was noted in the study. Attempts by service providers to modify the pain consisted of encouraging half of the patients to tolerate the pains during the procedure and use of oral analgesics and anti spasmolytic agent.

Infertility is a common indication for hysterosalpingography and on its own is associated with a lot of psychological disturbances. Though HSG is being replaced by Sonohysterogram [13]; it is still commonly performed in our environment as the primary method for evaluating the uterus and tubes in infertile women [2]. The Pain experienced during Hysterosalpingography is multifaceted. The sources of pain are from grasping 
Table 5. Satisfaction with care.

\begin{tabular}{|c|c|c|c|c|}
\hline \multirow{2}{*}{$\begin{array}{l}\text { Variable } \\
\text { Pre-procedure counselling }\end{array}$} & Frequency & Percentage & & \\
\hline & elling & & & \\
\hline Satisfied & 54 & 58.1 & & \\
\hline Not satisfied & 27 & 29.0 & & \\
\hline No opinion & 12 & 12.9 & & \\
\hline \multicolumn{5}{|l|}{ Pain management } \\
\hline Satisfied & 55 & 59.1 & & \\
\hline Not satisfied & 25 & 26.9 & & \\
\hline No opinion & 13 & 14.0 & & \\
\hline \multicolumn{5}{|l|}{ Post procedure care } \\
\hline Satisfied & 50 & 53.8 & & \\
\hline Not satisfied & 21 & 22.6 & & \\
\hline No opinion & 22 & 23.7 & & \\
\hline \multicolumn{3}{|c|}{ Level of satisfaction with pain management } & $\chi^{2}$ & p-value \\
\hline Satisfied (\%) & Not Satisfied (\%) & No opinion (\%) & & \\
\hline \multicolumn{5}{|l|}{ of pain } \\
\hline oderate $35(54.7)$ & $19(29.7)$ & $10(15.6)$ & & \\
\hline $20(69.0)$ & $6(20.7)$ & $3(10.3)$ & 1.72 & 0.423 \\
\hline
\end{tabular}

the cervix, distension of the uterus with contrast medium and peritoneal irritation as well as anxiety $[9,14]$. The long term consequences of painful experience include depression, chronic pain and rejection of care. There is also a psychological component to the pain due to fear, anxiety and experience shared by other women $[14,15]$. Overall, uptake of such vital test may be influenced by the fear of experiencing pain. Its care therefore demands varieties of approaches. The appropriate means of reducing pain and discomfort experienced during hysterosalpingogram has been a subject of several studies. Pre-procedure analgesics, topical anesthetics, intra-cervical block and use of balloon catheters have been associated with variable levels of pain relief $[\mathbf{8 , 9 , 1 1 , 1 6 ]}$. A perfect method is not yet established.

The satisfaction with care expressed by the women despite the painful experience is a reflection of user's expectation about quality of service. In our study, the user satisfaction was not statistically different amongst the women who had primary level education and post primary education. The procedure is a step towards resolving issues and the pain experienced is part of the process of finding solution to the problem. Also, Lack of awareness that the pain could be ameliorated by varieties of methods may account for satisfaction by half of the women. Women expected pain free procedure while a few women would want pre procedure analgesics administered. Pain free procedure makes the procedure widely accepted by end users and impacts on quality of life. This expectation of women should be met by service providers.

\section{Conclusion}

Hysterosalpingographic procedure is associated with variable levels of painful experience by the women. Though there is no perfect pain relieving agent for this procedure, providers need to take steps using multimodal options to ameliorate the pains experienced during the procedure to meet women's expectations.

\section{Competing interests}

The authors declare that they have no competing interests.

Authors' contributions

\begin{tabular}{|l|c|c|c|c|c|}
\hline Authors' Contributions & EMI & AUB & OO & BD & UAE \\
\hline Research Concept and Design & $\checkmark$ & $\checkmark$ & $\checkmark$ & $\checkmark$ & $\checkmark$ \\
\hline Collection and/or assembly of data & -- & $\checkmark$ & $\checkmark$ & -- & -- \\
\hline Data analysis and interpretation & $\checkmark$ & $\checkmark$ & $\checkmark$ & $\checkmark$ & $\checkmark$ \\
\hline Writing the article & $\checkmark$ & $\checkmark$ & $\checkmark$ & $\checkmark$ & $\checkmark$ \\
\hline Critical revision of the article & $\checkmark$ & $\checkmark$ & $\checkmark$ & $\checkmark$ & $\checkmark$ \\
\hline Final approval of article & $\checkmark$ & $\checkmark$ & $\checkmark$ & $\checkmark$ & $\checkmark$ \\
\hline Statistical Analysis & -- & -- & -- & -- & -- \\
\hline
\end{tabular}

Acknowledgements

We are grateful to our patients who participated in the study and to Dr. Affiong Oku for the Statistical analysis of the data.

Publication history

Editor: Erich Cosmi, University of Padua, Italy.

Received: 02-Aug-2018 Final Revised: 01-Sept-2018

Accepted: 16-Oct-2018 Published: 03-Nov-2018

\section{References}

1. Akinola R A, Akinola Ol and Fabamwo A O. Infertility in women : Hysterosalpingographic assessment of the fallopian tubes in Lagos, Nigeria. Educational Research and Review. 2009; 86-9. | Article 
2. Bello TO. Pattern of Tubal Pathology in Infertile Women on Hysterosalpingography in Ilorin, Nigeria. Annals of African Medicine. 2004; 77-9. | Article

3. Bukar M, Mustapha Z, Takai UI and Tahir A. Hysterosalpingographic findings in infertile women: a seven year review. Niger J Clin Pract. 2011; 14:168-70. | Article | PubMed

4. Khan MI, Jesmin S, Jerin J, Shermin S and Chowdhury TA. Hysterosalpingography in Infertility. Delta Med Coll J. 2014; 2:10-3.

5. Hussain M, Al Damegh S and Tabish A. Therapeutic efficacy of hysterosalpingography with special reference to application of hydrostatic pressure during the procedure. Int J Health Sci (Qassim). 2007; 1:223-7. | PubMed Abstract | PubMed FullText

6. Van Schoubroeck D, Van den Bosch T, Ameye L, Boes AS, D'Hooghe $T$ and Timmerman D. Pain during Fallopian-tube patency testing by hysterosalpingo-foam sonography. Ultrasound Obstet Gynecol. 2015; 45:346-50. | Article | PubMed

7. Kalantari M, Zadeh Modares S, Ahmadi F, Hazari V, Haghighi H, Chehrazi M and Razaghi M. Randomized double-blind clinical trial of eutectic mixture of local anesthetic creams in reducing pain during hysterosalpingography. Iran J Radiol. 2014; 11:e10513. | Article | PubMed Abstract | PubMed FullText

8. Unlu BS, Yilmazer M, Koken G, Arioz DT, Unlu E, Dogan Baki E, Kurttay C and Karacin $O$. Comparison of four different pain relief methods during hysterosalpingography: a randomized controlled study. Pain Res Manag. 2015; 20:107-11. | PubMed Abstract | PubMed FullText

9. Stoop D, De Brucker M, Haentjens P, Talebian A, de Mey J and Devroey P. Fast-release orodispersible tramadol as analgesia in hysterosalpingography with a metal cannula or a balloon catheter. Hum Reprod. 2010; 25:1451-7. | Article | PubMed

10. Varpula M. Hysterosalpingography with a balloon catheter versus a cannula: evaluation of patient pain. Radiology. 1989; 172:745-7. I Article | PubMed

11. Hindocha A, Beere L, O'Flynn H, Watson A and Ahmad G. Pain relief in hysterosalpingography. Cochrane Database Syst Rev. 2015; CD006106. I Article | PubMed

12. Tur-Kaspa I. Fear no pain: uterine cavity and tubal patency assessment tests should be pain free. Ultrasound Obstet Gynecol. 2012; 39:247-51. | Article I PubMed

13. Siam EM. Pregnancy outcome after hystero-salpingo-contrastsonography (HyCoSy) versus hysterosalpingography (HSG) using different contrast media. Middle East Fertil Soc J. 2011; 16:265-71. | Article

14. Park A, Quaas AM and Karl R. Predictors of Pain Associated With Hysterosalpingography (HSG): A Prospective Cohort Study. 2014; 1:1-4.

15. Okeji Mark C, Anakwe AngelMary C, Agwuna Kennedy K and Chinweuba $A$ nthonia $U$ EJC. Does preparatory information reduce anxiety and pain. Jokull J. 2013; 63:387-94.

16. Liberty G, Gal M, Halevy-Shalem T, Michaelson-Cohen R, Galoyan $\mathrm{N}$, Hyman J, Eldar-Geva T, Vatashsky E and Margalioth E. Lidocaineprilocaine (EMLA) cream as analgesia for hysterosalpingography: a prospective, randomized, controlled, double blinded study. Hum Reprod. 2007; 22:1335-9. | Article | PubMed

\section{Citation:}

Ekott MI, Bassey AU, Oboku O, Darlene B and Edet A. Women's experience with pain during hysterosalpingographic investigation in Calabar, South-South Nigeria. Res J Womens Health. 2018; 5:1. http://dx.doi.org/10.7243/2054-9865-5-1 